\title{
Imagen y tareas del sociólogo en la sociedad peruana
}

por

Aníbal Puijano

La Sociología Científica es una disciplina de reciente introducción en el Perú. Es inevitable, por eso, que la percepción social de la naturaleza de la ciencia, de los rasgos que tipifican a sus cultivadores y de la clase de tareas en las cuales pueden ser capaces de intervenir, contenga todavía muchos elementos que producen una visión distorsionada de la realidad y que impiden una más rápida y mejor adecuada institucionalización de las investigaciones científico-sociales.

Eso, unido al aún débil y vacilante nivel del cultivo de la Sociología en nuestro medio, parece también contribuir muy fuertemente, a que los propios sociólogos no logren todavía organizar una perspectiva coherente y clara de su imagen profesional y de la naturaleza de las tareas que tendrían que rea. lizar en el marco de una sociedad como la nuestra, muy especialmente, por cierto, entre los jóvenes que hacen su ingreso a este nuevo campo de actividad.

Es, pues, necesario plantear estos problemas, examinar algunas de sus implicaciones y consecuencias probables, en el nivel más enérgico de la conciencia y reclamar el debate sobre ellos, para que pueda irse abriendo un proceso de lúcida éaboración de, por lo menos, algunas de las mayores líneas de ideas que sirvan para orientar la formación y el trabajo de los hombres de ciencias sociales del Perú, y para construir una atmósfera de ideas y de conocimientos básicos, generalizables en la más amplia escala colectiva, con el propúsito de reorientar la percepción social sobre las características de nuestra sociedad y de sus problemas y del puesto de la sociología y de las demás ciencias sociales dentro de este cuadro.

No se trata, por supuesto, de olvidar la existencia de una cierta tradición sociológica anterior en el Perú. Tanto su en- 
señanza sistemática como disciplina independiente, como la aplicación de ideas sociológicas en el análisis de la historia y de la sociedad peruana, existen aquí desde hace mucho tiempo.

Tempranamente, a fines del siglo XIX, se publicó la Sociología cle Lima, de Capela, con un abundante material de información, que hasta ahora no ha merecido la atención de los actuales estudiosos.

A comienzos de este siglo, Mariano $\mathrm{H}$. Cornejo introdujo en la Universidad de San Marcos la enseñanza de la Sociología, como disciplina sistemática, y se constituyó en el más importante y solitario representante de la sociología académica tradicional en el país. Los méritos de su labor fueron internacionalmente reconocidos con su elección, en 1927, como Presidente del Instituto Internacional de Sociología, el más antiguo organismo de cooperación científica en este campo, y al que pertenecían las más ilustres figuras de la sociología académica de todo el mundo.

Naturalmente, las tendencias dominantes en la vida universitaria tradicional peruana, su permanente e infortunada alienación de la realidad circundante, producto en gran parte de la condición alienada y dependiente de la clase social que dotaba a la universidad de su orientación y de su liderazgo intelectual, condujeron a la sociología introducida en el mundo académico, a su aherrojamiento en la pura especulación, sin ningún intento de utilización del instrumental conceptual y metodológico disponible, para un acercamiento a la realidad social peruanage Lalobrae de Cornejo no trascendió nunca las fronteras estrictamente académicas y especulativas, y no llegó, ni siquiera dentro de este marco, a formar una tradición continuada de estos estudios, capaz de seguir el ritmo de desarrollo extraordinario de las ciencias sociales durante este siglo.

Por la misma época, otros profesores de gran relieve y audiencia nacional, intentaron con más que dudosa fortuna, organizar enfoques sobre algunos de nuestros problemas nacionales básicos. Tal, por ejemplo, el caso de Alejandro Deustua y sus varios ensayos sobre el indio, en relación con los problemas de la educación y de la cultura nacional, que forman en conjunto una obra hecha, casi enteramente, de puro prejuicio.

No puede caber vacilación alguna, al evaluar nuestra tradición sociológica anterior, para sostener que la única obra 
perdurable y válida fue la de gentes situadas fuera clel marco académico universitario, o enfrentados a él, como José Carlos Mariátegui, el más destacado ejemplo.

Después de Cornejo, la enseñanza y el desarrollo de la Sociología como disciplina sistemática, quedaron relegados a algun curso universitario de relativo interćs, sin ningún intento por abandonar la tendencia puramente especulativa y sin rastros de preocupación por mantenerse dentro del proceso de desarrollo y de reorientación científica constante, que caracteriza la situación de las ciencias sociales y de la Sociología en particular, sobre todo en los últimos treinta años. De todo ello, no podía resultar otra cosa que una especulación enteca, amorfa e inconsistente, de ninguna utilidad como instrumento de análisis de nuestra realidad socio-cultural.

Desde este punto de vista es, pues, correcto hablar de una reintroducción de la Sociología, desde hace unos pocos años. Esta perspectiva podría ayudar a explicar porqué las ideas existentes acerca de la sociología y del Sociólogo, en nuestro medio no son muy claras ni muy adecuadas a la realidad, y porqué sólo muy lentamente y bajo la presión de las urgencias de nuestra hora histórica, se va abriendo camino al interés por el desarrollo de estudios de esta naturaleza.

Sin duda, para un sector creciente en nuestra sociedad, la idea de la importancia de los estudios sociológicos es más y más penetrante. J Bero porqué yllde quéemanera concreta son importantes, y cuál es su genuina naturaleza, constituyen todavía un terreno problemático.

Importa, por eso, y mucho, en el momento mismo en que este interés se cristaliza en forma de exigencias sobre el pequeño número de gentes que comienzan en el país a dedicarse a estos estudios, y en la proliferación de centros universitarios de enseñanza e investigación sociológicas, intentar explorar este terreno problemático, elaborar algunos de los elementos básicos de la imagen de este nuevo profesional y de sus posibilidades efectivas de contribución a las tareas de una sociedad subdesarrollada, tanto para corregir ideas inadecuadas, como para limitar las excesivas ilusiones que suelen ser alimentadas sobre ello, aquí como en todas las sociedades donde se obliga, a la mayor parte de sus miembros, a alimentarse casi exclusivamente de esperanzas. 
ESTEREOTIPOS SOBRE LA SOCIOLOGIA Y SOBRE EL SOCIOLOGO EN EL PERU.

Puede decirse que son dos, principalmente, los grupos de ideas que expresan la confusión existente sobre la Sociología y sobre el Sociólogo, entre la gran mayoría de nuestra población implicada en esta problemática.

El primero de ellos, resultado probable de las caracterís. ticas de nuestra tradición sociológica anterior y del estilo característico de trabajo intelectual tradicional, confiere a la Sociología los siguientes rasgos:

1.-Es una disciplina puramente especulativa.

2.-Su contenido se refiere a grandes panoramas histórico-filosóficos acerca de la evolución de la humanidad.

3.-No puede ser considerada estrictamente una ciencia, porque no se adecúa al modelo de las ciencias naturales.

4.- Su utilidad concreta sería prácticamente inexistente, y su enseñanza y su cultivo, se justificarían por razones de formación de la personalidad y de "cultura general".

El segundo, en parte probablemente como resultado de una incompleta y distorsionada influencia del empiricismo de la sociología norteamericana y de la rápidas difusión de una perspectiva tecnológica para encarar los problemas económico-sociales, se sitúa en un ángulo opuesto al anterior.

Aquí la Sociología es considerada, fundamentalmente, como un conjunto de procedimientos para la obtención de datos muy concretos, de primera mano, acerca de hechos menudos como el número de hijos de una familia, el monto de sus ingresos, las características de las ocupaciones, etc., etc. Dentro de este mismo esquema, tampoco falta la confusión con la Etnografía, por su caracter descriptivo de los rasgos concretos que existen en una determinada población.

En el primer caso, el rol del Sociólogo se percibe, consecuentemente, como el de un especulador, más o menos amable y superficial o más o menos brillante y profundo, según los casos personales. En el segundo, el rol del Sociólogo se asimila al de un encuestador social, cuya misión es la recolección de datos concretos de primera mano, sobre la vida de los individuos o de grupos pequeños. 
La existencia de estos estereotipos acerca de la Sociología y del Sociólogo, no es un problema de poca importancia. Es necesario enfatizar su carácter de obstáculo serio para el desarrollo de la ciencia en el país, porque tiene una negativa influencia en las decisiones académicas y oficiales, respecto del fomento de centros de formación profesional en este campo; porque gravita deformadoramente sobre la elección de carreras profesionales entre los estudiantes; y porque no deja de influir en los propios estudiantes de la disciplina y entre los investigadores, caracterizando de un modo inadecuado sus posibilidades de participación en las tareas concernientes al desarrollo y cambio de la sociedad, y al desarrollo de la disciplina como tal.

Es muy fácil comprobar que, en determinados ambientes académicos, se sigue enseñando como Sociología un enredado amasijo de temas y reflexiones que provienen de trasmanidas versiones de la Filosofia Sncial y de la Filosofía de la Historia tradicionales. De esa manera, los estudiantes obtienen ina imagen completamente deformada de esta disciplina, como un vago y amorfo conjunto de reflexiones sobre la humanidad. De manera equivalente, en otros centros de estudio se enseña bajo el nombre de Sociología, algunas generalizaciones prematuras y arbitrarias, salpicadas de alguna estadística elemental, sobre algunos de los problemas más visibles de la sociedad.

De otro lado, podría decirse que en la actualidad, parte de la popularidad creciente de la Sociología, y en general de las ciencias sociales en Pelcpáís, lobedecena un fenómeno que se puede caracterizar como una moda, impuesta y difundida por el periodismo y por la preocupación acerca de los problemas del desarrollo económico. Junto a una genuina preocupación por alcanzar una comprensión inteligente y científica de la naturaleza y características de nuestra realidad sucio-cultural, la moda impone un cierto grado de dilusión y popularidad de los estudios de este tipo. Sobre estas bases, en todas las recientes universidades, en los centros de enseñanza post-secundaria y en el propio nivel secundario, se considera que es imprescindible incluir en los curricula cursos de Sociologia, y, si es posible, contar con un centro de formación profesional en esta ciencia.

Ocurre, sin embargo, que el establecimiento de estos cursos y centros de formación profesional y de investigación, revelan inmediatamente, en la mayor parte de los casos, que las perspectivas asignadas a ellos se fundan, inevitablemente, sobre alguno de los dos estereotipos señalados. 
Por esta razón, por ejemplo, en ciertas universidades recientes que se derivan de centros anteriores de formación de profesiones eminentemente técnicas y que se orientan básicamente en la misma dirección, se han establecido departamentos o facultades encargadas de la formación de especialistas en ciencias sociales, a los cuales se trata de desarrollar meramente como auxiliares del trabajo de las profesiones técnicas, y se les considera, por lo tanto, como eminentemente técnicos cllos mismos, cuya tarea más importante se reduce a la encuesta social. En tales condiciones, isi por alguna circunstancia comienza a verse claramente que las ciencias sociales, y particularmente la Sociología, tienen una naturaleza y una perspectiva enteramente diferente, y surgen intentos de reorientar de manera idónea el desarrollo de la enseñanza y de la investigación sociológicas, éstas ciencias son inmediatamente cercadas de un cordón sanitario de sospecha y de hostilidad.

La hostilidad y la sospecha no provienen, desde luego, solamente de las deformaciones en la imagen tradicional y popular de la Sociología y del Sociólogo. Probablemente, mucho más influyente en algunos casós característicos, es que esa imagen deformada está ligada claramente a muy conscientes preocupaciones por la defensa del orden social tradicional y por impedir que las ciencias sociales contribuyan a elaborar una conciencia social que, inevitablemente, enderezará la actitud y la conducta de las gentes-contra los factores que permiten la perduración del orden vigente de dominación social.

Si resulta que da Economía como ciencia no tiene únicamente el destino de ayudar a los empresarios a bajar sus costos de producción y a multiplicar sus posibilidades de beneficio. Si resulta que la Sociología no tiene como finalidad única o dominante, proporcionar datos y técnicas que permitan la manipulación de la opinión colectiva y particularmente la de los trabajadores, de modo que puedan aceptar alegremente su situación en la sociedad como un hecho natural e incontrovertible, los primeros en tratar de reducir las posibilidades de desarrollo de estas ciencias, son siempre las mismas autoridades o personas influyentes que, precisamente, hicieron lo necesario para la creación de cursos, centros de enseñanzas o de investigación en estas ciencias, con la esperanza de que a través de ellos se formaran profesionales dispuestos únicamente a mantenerse al servicio de los empresarios

Todo ello, pone de manifiesto de manera suficientemente clara, que la existencia de estos estereotipos sobre las ciencias sociales no solamente es un problema para el desarrollo 
de la investigación social en el país, sino también que su existencia se deriva y se fortalece de las mismas tendencias y factores que permiten la continuidad de la estructura tradicional de nuestra sociedad.

Intentando sacar a luz los elementos equívocos en que se fundan estos estereotipos, se puede contribuir, dentro de ciertos límites, a reorientar la percepción social acerca de la Sociología y del Sociólogo y, al mismo tiempo, a que los cultivadores de la disciplina puedan lograr una conciencia aguda de las relaciones entre la sociedad y la sociología, área de problemas que es parte de la más amplia problemática que forma el objeto de estudios de la Sociolgía del Conocimiento. Al hacerlo, no se debe ocultar la esperanza de que estos temas serán constantemente debatidos, una y otra vez, en el proceso de desarrollo de esta sociedad y de esta ciencia.

Básicamente, son tres los sectores de problemas sobre los cuales estos estereotipos manejan ideas completamente erróneas:

1) La naturaleza de la Sociología como ciencia;

2) El contenido y las finalidades de sus estudios y

3) La utilidad social de esta ciencia.

Es imprescindible elaborar algunas precisiones acerca de estos tres grupos de problemas. Pero, obviamente, la labor no podrá ser cumplida de manera exhaustiva dentro de los límites de un articulo corto. Conviene por eso, establecer aquí que el propósito del trabajo se contrae mas bien a levantar y plantear los problemas y a determinar algunos puntos de partida para el diálogo necesario.

\section{LA NATURALEZA DE LA SOCIOLOGIA COMO CIENCIA.}

En primer término, la Sociología no es una disciplina especulativa. No quiere decir esto que la especulación esté ausente en la Sociología. No lo está en ninguna de las ciencias. Pero ni esta especulación es gratuita, ni determina el carácter de la ciencia.

Ciertamente, las ideas sociológicas fueron desarrollándose en el seno de la Filosofía de la Historia y de la Filosotía Social. Cuando la Sociología surge como disciplina independiente, ambas disciplinas penetraban profundamente las formulaciones de los fundadores de esta ciencia y en ese marco la especulación era aún su contenido dominante. La obra de Comte, por ejemplo, ilustra plenamente esta situación, a 
diferencia de la de Marx, que, desde este punto de vista, constituye la fundación efectiva de la ciencia social contemporánca.

La Sociología contemporánea, fundamentalmente en los últimos decenios, se ha desprendido definitivamente de su umbilical atadura a la Filosofía Social, cuya naturaleza es básicamente cspeculativa, para convertirse enteramente en una ciencia fundada en la investigación concreta. Por ello, aunque dentro de un orden conceptual muy amplio la Sociología está inocultable e inevitablemente ligada a la Filosofía Social y a la Filosofía de la Historia, no debe perderse de vista el hecho de que dispone de una esfera autónoma.

IEn tanto que ciencia, y desde el punto de vista que aquí interesa, la Sociología se caracteriza por la elaboración de un cuerpo de conocinientos y de ideas sistemáticamente organizado, que se funda en la investigación concreta de los núcleos de fenómenos y de problemas sociales correspondientes. Esto es, en una amplia y creciente medida, las ideas se subordinan a los hechos y se desarrollan a partir de ellos. Las hipótesis y teorías no son, pues, gratuitas, no se formulan de manera puramente apriorística o simplemente impresionistica, y no se autoalimentan sino en parte. $Y$, lo que es aecisivo, no se formulan sino en tanto que sistemas de conceptos destinados a su verificación en la investigación empírica concreta.

De allí, en consecuencia, queelà Sociología no debe ser, tampoco, percibida y desarrollada meramente como un conjunto de procedimientos para recopilar sy" catalogar datos menudos de primera mano, acerca de la vida de grupos e individuos humanos, por rigurosa y sistemáticamente que ello pudiera hacerse. De lo que se trata, ante todo, es de la búsqueda, a través de los datos, de las regularidades o uniformidades que caracterizan el modo de producción y de existencia de los fenómenos sociales, sobre los cuales los datos concretos sólo pųeden presentarse como referentes existenciale's segmentarios:

La ciencia sociológica contemporánea no constituye, de ninguna manera, ni solamente un conjunto de vagas y amorfas reflexiones acerca de la sociedad, o brillantes y profundas, pero impresionísticas, especulaciones sobre ella, sin fundamento empírico concreto, organizado y elaborado de manera rigurosamente sistemática; ni solamente un catálogo de datos sobre problemas y fenómenos sociales, cuya recolección no ha sido guiada por un cuerpo consistente y sistemá. 
ticamente organizado de ideas y de conocimientos, es decir, por hipótesis y teorías, aptas para diferenciar y delimitar esferas de fenómenos y reconstruir en la abstracción su naturaleza total y su comportamiento.

Por el contrario,' la ciencia sociológica contemporánea se caracteriza, precisamente, por la permanente e insustituible interdependencia dialéctica entre la teoría, que guía y orienta la búsqueda y organización de los datos concretos, que realizada de manera sistemática se denomina investigación concreta y empírica, y los resultados de esta labor que permiten modificar, ampliar, profundizar e innovar, en general, constantemente la teoria. La ciencia sociológica no puede concebirse de otra manera!

De esa manera, la investigación sociológica implica, al mismo tiempo, el uso de un aparato conceptual incesantemente refinado, y de un instrumental metodológico que, tanto en el nivel de los principios que guían la investigación, como - en el nivel, de las técnicas, operaciones y procedimientos de recopilación y elaboración de los datos, se desarrolla y se perfecciona sin pausa.

- Sin duda, lo que caracteriza el vertiginoso proceso de desarrollo de la Sociología y de las demás ciencias sociales hasta aquí, es justamente la elaboración cada vez más rigurosa y sistemática del análisis conceptual en la teoría, y la búsqueda y refinamiento de instrumentos de medición y de verificación de los datos, teada vez más seguros y confiables, en la metodología.

\section{EL CAMPO Y LAS FINALIDADES CIENTIFICAS DE LOS ES- TUDIOS SOCIOLOGICOS.}

Todo lo anterior, significa que las investigaciones sociológicas no producen lo que un sociólogo francés ha llamado "ies grandes machines d'opera historique" ridiculizando las deformaciones de la especulación gratuita e impresionística acerca de la sociedad y de la historia, que constituyen el contenido de grandes esquemas inconfirmables de la evolución y el sentido de la historia humana. Tampoco, lo que tantos quisieran, al parecer, solamente grandes catálogos de datos concretos rigurosamente confirmados, sobre múltiples aspectos de la vida concreta de las gentes, utilizables para ilustrar, por su mismo carácter inorgánico, cualquier género de proposiciones.

Del mismo modo que las ciencias naturales, individualmente y en conjunto, suponen la elaboración de un conjunto 
sistemáticamente construído, de conocimientos e ideas, teórica y concretamente establecidos, acerca del modo de producción y de existencia de los fenómenos naturales, las ciencias sociales, y dentro de ellas la más abstracta, la Sociología, suponen la elaboración de un cuerpo equivalente de conocimientos y de ideas sistemáticamente organizado, acerca de la vida del hombre en sociedad.

Ello implica, por lo tanto, 'que la ciencia sociológica no contiene solamente datos o conocimientos dispersos, o regularidades empíricas, sino también un cierto número de verdades generales o "leyes", en tanto que sistemas de explicación e interpretación de determinados núcleos de fenómenos que tienen lugar en la vida social humana!'

La Sociología no pretende, sin embargo, el estudio de todos y cada uno de los aspectos que puede ofrecer la sociedad humana.' La Sociología es sólo una dentro de muchas ciencias cuyo objeto de estudios es la vida del hombre en sociedad.' $\mathrm{Y}$ aunque, por fortuna, los linderos entre tales ciencias ya no son abismos infranqueables y se desarrolla en la actualidad una vigorosa tendencia a la reintegración del saber sobre la sociedad, existen entre ellas distinciones específicas que no serán examinadas en esta ocasión.

Bastará, por ahora, señalar que lo que caracteriza a la Sociología en relación a las demás ciencias sociales, es su énfasis en la naturaleza de la sociedad como totalidad, cuyos componentes son interdependientes entre si $y$ con el conjunto.' De ello se deriva el nivel necesariamente más alto de abstracción. Los fenómenos sociales son, en esta perspectiva, fenómenos sociales totales, cuyos elementos constitutivos sólo pueden ser objeto de aislamiento analítico y metodológico, pero que forman en la realidad un único y viviente complejo, $y$, por consecuencia, ningún aspecto segmentarizado para fines de análisis puede ser adecuadamente explicado e interpretado sino en su relación con los demás, tanto con los que coexisten en la misma esfera temporal, como con los que provienen de la secuencia de desarrollo anterior. $x$

\section{EL VALOR SOCIAL DE LA SOCIOLOGIA}

Aparece claro en esta etapa del análisis, que la utilidad de la Sociología no consiste en ofrecer al que lo necesite para sus fines particulares, ideas generales acerca de la sociedad y de su historia, o datos concretos de primera mano sobre la vida de las gentes en un instante histórico determinado. 
A nadie se le ocurriría dudar ahora sobre la clase de utilidad de las ciencias naturales. Todo el mundo comprende, por lo general, que ellas permiten la predicción y el control de los fenómenos naturales, posibilitando la intervención racional y consciente de los hombres, en beneficio de la sociedad, sobre el mundo de la naturaleza.

De idéntica manera, no debiera caber ninguna vacilación para comprender que fel valor de las ciencias de la sociedad y en este caso de la Sociologia, consiste en la posibilidad de predecir los fenómenos sociales, permitiendo al hombre inter venir de manera racional y consciente, es decir libre, en la organización de las condiciones de su propia existencia.

Sin las ciencias sociales, los hombres han organizado y organizan constantemente las formas concretas de su existencia, de manera enteramente inconsciente, al margen de su voluntad y de su decisión consciente, o solamente pueden hacerlo en una limitada y deformada medida, sobre la base de su experiencia empírica, de sus prejuicios, de sus estereotipos y de los intereses de grupo de los poderosos.

A nadie se le oculta o se le debe ocultar, que la experiencia inmediata sólo puede fundar un tipo de conocimiento limitado y contingente. Sobre esta base no es posible pensar en el desarrollo de la posibilidad humana de intervención racional y consciente en su existencia histórica, de modo tal que permita la fundaciónede una vida genuinamente humana, despojada de condiciones engendradoras de injusticia.

Revelar los supuestos y los factores implícitos en la conducta humana, para que todos sepan a qué atenerse y puedan optar con conocimiento de causa, racionalizar las posibilidades y los límites de la intervención consciente en la organización de las condiciones concretas de la existencia social, poner en sus manos la brasa de la decisión consciente, liberarlo de costras de mitos y de verdades a medias, y de la manipulación de su conciencia por los recursos del poder, es la promesa desplegada ahora ante el hombre por las ciencias de la sociedad. No hay modo de exagerar su importancia;

Subryando esta línea de pensamiento en la obra y la lucha de Wright Mills, he dejado dicho en otra parte que: $\Gamma$ "el valor social de una ciencia de la sociedad, es el de equipar a los hombres con los instrumentos del conocimiento científico de sus problemas dentro de la sociedad, clarificar permanentemente su conciencia social, para que replanteándose 
sin pausa el sentido de su historia ${ }_{h}$ pueda liberarse de las alienaciones sociales de su tiempo" (1)

\section{PROBLEMAS Y DIFICULTADES PARA EL PROCESO DE INS- TITUCIONALIZACION DE LA SOCIOLOGIA.}

Establecidos, así, algunos de los elementos básicos para la comprensión de la naturaleza y el valor social de la Sociología, es indispensable ahora clarificar en alguna medida los límites y los riesgos más evidentes que se contienen en la perspectiva inmediata del desarrollo de la Sociología en el Perú y en Latinoamérica en su conjunto, con el propósito de delimitar, hasta donde sea posible, la naturaleza de las tareas de los sociólogos y las dificultades para realizarlas.

Las dificultades provienen tanto del propio nivel de desarrollo de las ciencias sociales, como del marco social e institucional dentro del cual se trata de implantarlas. Entre ambas esferas de problemas existe necesariamente cierto tipo de interdependencia, que no es, por supuesto, correspondencia estricta y permanente.

Es verdad que la Sociología se desarrolla rápidamente, $\mathrm{y}$ ejerce una creciente influencia sobre las demás ciencias sociales y, en general, sobre la conciencia social contemporánea. Hoy día es posible señalar con Sorokin, la tendencia a la "sociologización" de las ciencias sociales. El volumen de las investigaciones concretas, especialmente en las socieda. des industrializadas, aumenta de manera que ningún sociólogo puede seguirlas al día en su totalidad. El instrumental metodológico se "refina constantemente y sus técnicas de medición utilizan recursos matemáticos de muy elevado nivel. El cuerpo teórico de la disciplina es, por eso, cada vez más rico y cada vez más confiable

Sin embargo, los propios sociólogos en primer término tienen y deben tener la más clara conciencia de las limitaciones de ese desarrollo jLa Sociología es una de las más jóvenes ciencias; su desarrollo dentro de las orientaciones actuales data, en verdad, solamente de los últimos treinta o cuarenta años. Y por ésta y otras más complejas razones, es indudable que no puede exhibir todavía el rigor, la madurez y la seguridad de las ciencias naturales?

No cabe, por lo tanto, hacerse excesivas y prematuras espectativas sobre la seguridad con que la Sociología puede responder a las demandas y a las exigencias que una sociedad como la nuestra puede formularle acerca de sus proble-

(1) ANIBAL QUiJano O.: "Wright Mills". Revista del Musco Naclonal. Lima, 1963. 
mas. $Y$, sobre todo, no hay todavía lugar para derivar del estado actual de las ciencias sociales una sucrte de ingenicria social, utilizable como función meramente técnica ,al margen de postulados valóricos, como si se tratara de un saber establecido a la manera de la Química, u otras ciencias de la naturaleza.

'De una parte, el hecho mismo de su reciente introducción, como disciplina científica en el país, pone de relieve el nivel precario y el volumen incipiente de las investigaciones básicas sobre nuestra realidad socio-cultural y sobre nuestra historia. Es totalmente ilegítimo e inútil, por eso, pretender explicar e interpretar la naturaleza actual de nuestra sociedad, las características y tendencias de los fenómenos específicos que tienen lugar en ella, por la aplicación mecánica de los principios generales de la ciencia, o por la aplicación de regularidades empiricas registradas en sociedades y culturas profundamente diferentes, sin contar con el material resultante de nuestras propias investigaciones sobre nuestra propia sociedad.

$\mathrm{Y}$ éste, fuera de toda duda, es uno de los problemas centrales planteados en la implantación de la Sociología y otras ciencias sociales en el Perú y en Latinoamérica. // La Sociología no es solamente una ciencia joven y de reciente desarrollo. Para lo que aquí interesa, es tanto más importante tener en cuenta que este desarrollo se ha producido en sociedades profundamente diferentes de las nuestras, del mundo andino en particular, $y$, sobre todo, en sociedades que contienen centros actuales e históricos de poder sobre las nuestras como sobre otras en situación equivalente.

Esto es, el cuerpo más importante de conocimientos y de ideas que se organizan ahora dentro de la Sociología es, de una parte, el resultado de investigaciones llevadas a cabo en su mayor parte en las sociedades industrializadas del bloque occidental, y sólo en mínima y fragmentaria escala en otras sociedades como las incluidas en Latinoamérici. De otra parte, los modos de percepción de la realidad histórico-social, los enfoques teóricos y los principios metodo. lógicos, corresponden en gran medida a los intereses concre:tos de los centros de poder existentes en esas sociedades.'

Para nadie es ahora oculto, el hecho que las ciencias sociales elaboradas en las sociedades industrializadas, y de manera especial en los Estados Unidos, contienen proporcione: dominantes de etnocentrismo y, lo que no es otro modo de denominar lo mismo, de provincianismo. No pueden ser ad- 
mitidas en su pretensión de universalidad, sin una firme y iuidadosa criba.

Nada de esto quiere decir, es necesario enfatizarlo, que la Sociología desarrollada en las sociedades industrializadas en un sistema de mercado, deba ser rechazada simplemente, en fardo; que no sea el necesario punto de partida del desarrollo de esta ciencia, que no contenga elementos universalmente válidos y que todo en ella corresponda solamente a intereses sociales universalmente dominantes, como se la suele hacer aparecer malevolentemente entre algunas gentes. No debe tampoco quedar sin ser dicho claramente, que en este preciso período se asiste a una vigorosa tendencia de reorientación de las ciencias sociales en aquellas sociedades, y que puede hablarse en algunos casos de un redescubrimiento de la naturaleza de la realidad histórico-social.

El vertiginoso y enmarañado proceso de cambio social en todo el mundo, la emergencia combativa de las nuevas nacionalidades, la desintegración del colonialismo y el deterioro del imperialismo cconómico, la tumultuosa exigencia de los puebios subdesarrollados por compartir todos los be neficios de la cultura contemporánea, no tienen solamente los impactos políticos que todos presenciamos, y la preocupación internacional por el desarrollo económico. Tanto o más decisivos que todos estos efectos, son aquellos que se producen a nivel de la conciencia científica. No solamente porque nadie, científico o no, puede dejar de serafectadoprofundamente en la actitud frente al destino de los hombres contemporáneos, en sus más profundas estructuras perceptivas de estos problemas, sino también porque la masa de datos que provienen ahora de las investigaciones que se realizan en las sociedades no-occidentales, en pleno proceso de cambio, comienzan a indicar con nitidez que los sistemas de explicación de los fenómenos sociales, resultantes de la investigación, casi únicamente en las sociedades occidentales industrializadas, así como los principios y técnicas de investigación concreta, no tienen todos la pretendida validez universal, que es urgente encontrar un camino de reorientación de algunos de los más endurecidos núcleos de ideas y de enfoques en las ciencias sociales, de reformulación de los que contienen elementos verificados, de elaboración de enfoques, conceptos y métodos nuevos de estudio para fenómenos nuevos.

Porque no solamente era desconocido, poco o mal investigado, lo que se contiene en las sociedades subdesarrolladas en proceso de cambio, sino porque lo que ahora ocurre es 
nuevo en gran medida. Porque son nuevos los fenómenos viejos pero no conocidos, para la ciencia, y son nuevos desnudamente los fenómenos que caracterizan gran parte deí proceso de cambio contemporáneo.

Frente a todas estas circunstancias, 'las tendencias todavía en curso, de implantación mecánica y burdamente imitativa de los enfoques teóricos y metodológicos provenientes de otras sociedades, en el contexto peruano y latinoamericano en general, no pueden ser consideradas sino como la pro. longación de un colonialismo cultural que impregna la totalidad de nuestra actividad en este campo:

El Perú, como todas las demás de Latinoamérica, como las del área andina, en especial, es una sociedad dependiente. No lo es sólo económica y políticamente. La alienación cultural que caracterizó a las anteriores generaciones de estudiosos, provenientes de grupos cuya vida integra estaba volcada hacia la imitación permanente de lo externo a sus propias circunstancias, es todavia vigente en gran parte. El proceso de desalienación es todavía reciente, incierto y pobre en resultados, ante todo en el nivel de la labor intelectual en general. 'La introducción de conceptos y técnicas de investigación, desarrolladas para realidades largamente diferentes, sin ninguna duda acerca de su validez universal y de su capacidad para dar cuenta de nuestra propia realidad socio-cultural, es uno de los frutos viejos de esta dependencia.

No hay aquí ningủn sentido de torpe nacionalismo científico, de chauvinismo cultural, como la deshonestidad y la malevolencia no dejarán decquerer creer.SOSe trata simplemente de destacar un factor psicológico-social cluramente importante, que se levanta como un gran obstáculo para las posibilidades de contribuir al desarrollo de la ciencia - y porqué no decirlo a toda voz - y de la cultura universal, desde nuestra propia perspectiva. Ajeno, por completo, todo ello, a toda pretensión de un nuevo etnocentrisino, de un nuevo parroquialismo, sin ánimo y sin poder de reconstruir la historia y la cultura del mundo desde el punto de vista de intereses de campanario, pero dotado de todo su derecho a elaborar conceptos nuevos para fenómenos nuevos, y a introducirlos en el cuerpo común y universal de nuestras ciencias. A la construcción de un suelo propio de conocimientos acerca de nuestra propia circunstancia, de una patria cultural y espiritual beneficiada de todo el aporte universal y de lo que proviene de nuestra propia historia.

Dos son los núcleos de ideas que caracterizan a las ten- 
dencias dominantes en la ciencia sociológica contemporánea, y que deben ser puestos en evidencia y debate entre nosotros, porque son ellos los que limitan y deforman la perspectiva cabal de la realidad histórico-social. De una parte, la radical ahistoricidad que subyace en los cuadros conceptuales y en los principios metodológicos que les corresponden, especialmente en la sociología norteamericana. De otra parte, la pretensión de elaborar una ciencia social despojada de posiciones de valor:!

El estructural funcionalismo, en todas sus variantes y matices, es como se sabe, la tendencia dominante hasta la fecha en la sociología norteamericana y su influencia se difunde por todo el resto del mundo; en Latinoamérica, debido al hecho de que la mayor parte de nuestros científicos sociales derivan su formación de centros universitarios de ese país o de centros latinoamericanos donde esta corriente se impone como la única legítimamente científica. No sólo su aparato conceptual y metodológico efectivo, sino también su jerga característica, difundida ya hasta en el nivel periodístico más banal, pasan por ser la llave maestra de explicación de los fenómenos sociales en cualquier latitud.

La ahistoricidad en el enfoque de los fenómenos sociales, y la pretensión de una ciencia social despojada de posiciones de valor, son precisamente, los dōs elementos característicos que vician la tendencia estructural funcionalista, y que, sin embargo, dominan ty moldean las estructuras perceptivas de una gran parte de los sociólogos contemporáneos.'

La concepción de la sociedad como una totalidad cuyos elementos se integran de manera rigurosamente sistemática y que, por lo mismo, existe siempre en estado de equilibrio $y$ no de transformación incesante. El énfasis en que el equilibrio debe ser mantenido y las modificaciones revolucionarias significan la desintegración de la sociedad. La elaboración de sistemas de explicación e interpretación de los fenómenos sociales. eliminando los factores que provienen de la historia y sustituyéndolos por la mera relación funcional de correspondencia entre los elementos actuales entre sí y con el conjunto. La noción de que los elementos de una sociedad, en un instante histórico determinado, existen porque desempeñan una función, negativa o positiva, y que esa existencia es por lo tanto enteramente legítima. La imagen de la sociedad de la cual se elimina el conflicto como uno de los modos fundamentales de integración e interdependencia de sus elementos, y el énfasis permanente en un sistema de 
equilibrio armónico en el cual todos los sectores sociales participan en un único sistema de valores. La noción del poder como un conjunto de recursos que los miembros de la sociedad otorgan consensualmente a individuos y grupos determinados, para llevar a cabo los fines generales de la sociedad, en vez de recursos que tales grupos disponen como consecuencia de su posición dominante en la sociedad, robustecida y mantenida por los mecanismos del poder. Todo ello, es en la actualidad, el conjunto de elementos teóricos que caracterizan la vertiente estructural-funcionalista de las ciencias sociales contemporáneas, en sus diversas varian. tes y matices, inclusive en las más críticas."

Y La sociedad, desde este punto de vista, es un fenómeno dado y no dándose, una realidad predominantemente estática y en equilibrio, en la cual los cambios sólo pueden ocurrir siempre de manera molecular y lenta, a medida que cada uno de los elementos de la sociedad se van modificando simultáneamente.

- Estos elementos conceptuales que integran la teoría estructural-funcionalista de la sociedad, denuncian claramente un modo totalmente ahistórico de percibir los fenómenos sociales. No solamente, en el sentido en que la secuencia histórica es eliminada de la explicación e interpretación, en aras de la mera relación funcional momentánea, sino, sobre todo, en tanto que percepción de la sociedad en general como algo principalmente lestático, comoedado, no obstante la admisión verbal y formal de la necesidad histórica del cambio social.

Como es fácil comprender, la teoría del cambio que se deriva de este enfoque estructural-funcionalista, no puede ser capaz de dar cuenta de la naturaleza real de los fenómenos, se ha revelado cada vez más como absolutamente insuficiente, y, más aún, deformadora. No es ninguna casualidad que sólo muy recientemente, bajo los golpes de la realidad contemporánea, comienza a generalizarse la preocupación por la sociología del conflicto en la sociología norteamericana dominante, $\mathrm{y}$ que aquella nazca espuriamente, fundada ante todo en los problemas derivados de los conflictos militares internacionales.

Para sociedades como las nuestras, atravesando un rápido, convulsivo y cońllictivo proceso de cambio, la aplicación mecánica e indiscriminada del aparato conceptual y metodológico al uso, en el estudio de nuestra realidad socio-cultural, sólo podría dar como resultado una imagen enteramente 
distorsionada de la sociedad y de sus procesos de cambio, e impediría la fundación de una rráctica racional acerca de ellos.

En verdad, gran parte de las formulaciones teóricas de la actual sociología norteamericana, particularmente las que se construyen formalísticamente, pero de la misma manera las que sirven de orientación a los estudios sobre fenómenos de distribución del poder social, no pueden dejar de ser consideradas, en cierto sentido, como una manera de revestir con el prestigioso lenguaje científico muchos de los estereotipos habituales en la propia sociedad, y como un sistema de legitimación y justificación de lo existente. En la medida en que ello es así, corresponden abiertamente a los intereses sociales dominantes de la propia sociedad, y su difusión dominante en el resto del mundo no se basa solamente en la incapacidad crítica de quienes lo admiten sin discusión, sino también en la correspondencia de intereses sociales.

Lo notable, sin embargo, es que es precisamente esta corriente, que defiende encarnizadamente la posibilidad de una ciencia de la sociedad despojada de valores, de la misma manera que las ciencias de la naturaleza. De este modo, la imagen de la sociedad proporcionada por estas tendencias aparecería como rigurosamente objetiva, universalmente válida. En el extremo, eso supone que la sociedad en la cual se elaboran estos enfoques es no solamente la sociedad justa sino lisamente la sociedad.

En el fondo, rese necesariol isubrayarto," es un tipo característico de contrabando intelectual. La ciencia, cualesquiera que ella sea, no consiste solamente en un conjunto de ideas y de conocimientos acerca de un sector de la realidad, sino en un modo de relación entre el hombre y esa realidad.! Es, en esta perspectiva, una parte de la práxis histórica global. En esa condición, no puede tener cabida legítima la posibilidad de que la comprensión racional del hombre acerca de los factores que participan en su vida social, pueda estar despojada de posiciones de valor.

En este caso, como siempre, lo que se echa por la puerta entra por la ventana. Es decir, ningún individuo que estudia la sociedad, mucho más todavía cuando se trata de la suya, puede realmente despojarse totalmente de todos los elementos que conforman la estructura más profunda de su personalidad, en términos de actitudes, motivaciones y valores, ni es posible que tenga siempre una completa conciencia acerca de ellos: Por lo tanto, aunque sin duda alguna es legí- 
tima la aspiración de alcanzar una plena libertad en la elaboración científica, de todos los elementos subjetivos que puedan impregnar las conclusiones, es indispensable no confundir esa aspiración con las posibilidades insertas en la realidad.

Lejos, en consecuencia, de pretender una sociología despojada de valores, es indispensable tratar de explicitar sin disfraces la última posición de valor de que se tenga conciencia, y discutir su validez o su legitimidad, cuando se parte desde ella para el estudio de los fenómenos sociales, para que nadie pueda llamarse a engaño y sepa cabalmente a qué atenerse respecto de las conclusiones.

En un lúcido y enjundioso ensayo, Alvin Gouldner, a quien se le reconoce como uno de los más imporantes sociólogos norteamericanos, ha explicado con claridad los origenes y las consecuencias de esta idea de una ciencia de la sociedad libre de valores y la ha caracterizado, adecuadamente, como uno de los mitos más endurecidos de la sociología contemporánea. (2)

"La ciencia supone un proceso de racionalización de las relaciones entre el hombre y sus circunstancias, sean éstas parte de la naturaleza o de la sociedad. De manera especial en sociedades como las nuestras, es necesario relievar en todo su vigor, la necesidad de contribuir con todas las fuerzas al proceso de racionalización de las relaciones entre los hombres. El científico social no es solamente un pozo de conocimiento más o menos válidos acerca de la sociedad, sino también es un hombre con una actitud $y$ una posición frente a esa realidad, que se deriva tanto de sus conocimientos acerca de ella, como de su propia posición en la sociedad. En tanto que hace ciencia, por lo tanto, está comprometido con una actitud y una posición frente a la realidad social, con todos los riesgos y todas las implicaciones incorporadas a esta condición!'

Nada de eso, desde luego, significa que el hombre de ciencia confunda sus deseos con la realidad, o que retuerza los datos para meterlos dentro de esquemas mentales guiados principalmente por su posición valórica o ideológica. Por el contrario, la única posibilidad que tiene de despojarse de la presión de los elementos arbitrarios de la subjetividad, es tratar de explicitarlos, discutirlos, confrontarlos honestamente con los datos y llevar hasta la más profunda estructura

(2) ALVIN GOULDNER: "Antiminotauro". En: Sociology on Trlal, Vidich and Stein, cds. Prentice - Hall, 1963. 
de su personalidad, los resultados. Ser hombre de ciencia no es, pues, tener una profesión que permita ganarse la existencia cotidiana; es un modo de ser hombre en una determinada realidad.

Aquí se revela en toda su magnitud, la conexión entrañable que existe entre la sociología o cualquiera de las demás ciencias sociales, con la filosofía social y la filosofía de la historia. Estudiar al hombre en sociedad, es parte del interés más profundo por el destino concreto de los hombres, es parte de la búsqueda de las mejores posibilidades de eliminación de las alienaciones sociales existentes. Esto no cambia si el sociólogo como individuo tiene o no conciencia de ello o esté o no concernido con ello. Pero, naturalmente, la sensibilidad que permite acercarse a una comprensión inteligente de los fenómenos sociales y de los problemas humanos im. plicados en ellos, no está realmente ausente ni siquiera en las más aéreas torres de marfil.

Es tiempo ahora, precisamente, para enfrentar todos estos problemas con honestidad y con audacia.

El desarrollo de las ciencias sociales en una sociedad sin tradición continuada y válida de ellas, está rodeada al mismo tiempo de ventajas y de desventajas. Estas son obvias: la inexistencia de gentes con la formación adecuada, la carencia de recursos institucionales y financieros idóneos, la magnitud de la tarea misma, las deformaciones previas en la conciencia colectiva acerča de das ciencias, etc. Las ventajas son menos evidentes. Para lo que aquí importa, conviene señalar la principal@lá posibilidad dercomenzar en el último nivel del desarrollo de estas ciencias en el resto del mundo, sin tener que repetir la experiencia previa, sin tener que cargar con el peso muerto de mitos, deformaciones y dificultades anteriores que, naturalmente, impregnan todavía el desarrollo de estas ciencias en los países donde tuvieron su nacimiento y desarrollo inicial. Es decir, es posible tener una clara conciencia de estos problemas, aprovechar de la experiencia ajena, planificar racionalmente -hasta donde las circunstancias lo permitan - las vías más adecuadas y las orientaciones más valederas de desarrollo de las investigaciones, y de construcción de la ciencia.

Estas ventajas no sabrían ser correctamente utilizadas, si desde ahora no tuviéramos el coraje de plantearnos esta problemática en toda su profundidad y su magnitud. Las ciencias sociales no conforman, todavía, un saber establecido a la manera de algunas de las ciencias naturales y algunos de 
sus niveles. El vertiginoso crecimiento de las investigaciones, la novedad de los propios fenómenos que hay que investigar, por la velocidad de los cambios sociales, obligan a una constante reorientación de la investigación, y gran parte de lo hecho antes entra rápidamente en desuso y es indispensabíe redefinir los puntos de partida y las perspectivas, como condición de eliminar algunas de las mayores fuentes de deformación de nuestras posibilidades.

El Perú está, justamente ahora, urgido del debate acerca de cada uno de estos problemas y los jóvenes que ingresan en las ciencias sociales no pueden ser mantenidos al margen de esta preocupación.

\section{EL MARCO SOCIAL E INSTITUCIONAL.}

Otra fuente de problemas y de dificultades en el desarrollo de la sociología en el país, surge de la naturaleza del marco social global en el cual se trata de institucionalizar y desarrollar la disciplina, así como del marco institucional inmediato en cuyo seno se forman y trabajan los científicos sociales.

En el primer nivel, son dos los problemas que deben ser levantados en el punto de partida: 1) El carácter todavía en gran parte tradicional de la estructura global de la sociedad y el carácter no-racional del proceso de modernización. 2) El poder de los intereses sociales que se derivan de lo anterior, $y$ que tienden a fortalecer las tendencias tradicionales y modernas no-racionales.ccinelli Converso»

Puesto que la ciencia moderna es ella misma parte del proceso general de racionalización de las relaciones entre el hombre y sus circunstancias, y es uno de los más decisivos factores que contribuyen a él, es evidente que su desarrollo no puede ser realizado plenamente sino en la medida en que la propia sociedad se transforma y se va haciendo apta para aceptar los resultados de la investigación científica y para incorporarlos en la práctica cotidiana de organización y reorganización permanente de las condiciones concretas de su existencia.

Eso significa que, en una medida creciente, el desarrollo de la ciencia social es incompatible con el dominio de formas tradicionales de la estructura general de la sociedad, no solamente en tanto que tradición que se deriva de la anterior experiencia histórica, sino también en tanto que tradición que se moderniza por vias no-racionales, esto, es adoptando for- 
mas nuevas que no conducen, necesariamente, a la transformación efectiva del carácter fundamental de la estructura, y que no se fundan en la admisión resuelta de la necesidad del cambio. En este sentido, hay evolución de la estructura, pero no hay una transformación radical de ella. Este fenómeno ha sido ilustrado con feliz claridad en un pasaje de la celebrada novela de Tomaso di Lampedusa, el Gatopardo; cuando el Príncipe de Salina reprocha a su sobrino el haberse adherido a las huestes garibaldinas, el sobrino responde con una frase admirable por lo que revela:" "Mira tío, si queremos que todo siga igual, es necesario que todo cambie. Me explico?". Y es esto, exactamente, lo que ocurre con la tradición que se moderniza sin dejar de ser.

Nadie que tenga ojos para ver, puede tener demasiadas dudas de que en la actual escena latinoamericana en general y peruana en particular, todos los esfuerzos de los grupos dominantes de la sociedad llevan, precisamente, a este camino de la modernización de la tradición, para evitar por todos los medios, incluyendo las bombas napalm, la transformación profunda y radical de las estructuras sociales que les permiten la perpetuación de su poder en la sociedad.'

En estas circunstancias, es inevitable que existen tendencias muy pronunciadas para tratar de convertir a las ciencias sociales en una suerte de instrumento técnico, de manipulación de datos, con el objeto de hacerlas servir, primordialmente, a la tinalidad de la modernización de las estructuras de la sociedad y de evitar su efectiva transformación. El énfasis en la "neutralidad" de la ciencia y la "objetividad", son parte de toda esta realidad.

I Obstaculizar por todos los medios la investigación de la estructura profunda de la sociedad que dominan, evitar que se pueda poner en cuestión la legitimidad y la justicia de esa estructura, enfatizar los problemas de adaptación-inadaptación individual o de pequeños grupos a una estructura dada que se asume natural, y desviar la reflexión de los problemas histórico-filosóficos implicados en los alcances mayores de la construcción de la ciencia social, no puede dejar de ser el esfuerzo permanente de todos los grupos de poder dominante dentro de esta sociedad.l

Todo ello significa, claramente, que si los científicos sociales no tienen la más lúcida conciencia de estos riesgos, las deformaciones en la construcción de la ciencia social, en la construcción de una imagen científica de la sociedad que corresponda a la realidad, no podrán ser evitadas. Los soció- 
logos, en primer término, necesitan estar permanentemente en guardia contra esa perspectiva.

El carácter tradicional de las estructuras generales de la sociedad, en cualquiera de sus formas, la vieja o la nueva, implica necesariamente que la masa de la población tiende a explicarse y a interpretar sus circunstancias recurriendo principalmente al fondo tradicional de_concepciones precientíficas de los problemas, mitos, semi-verdades, que se alimentan de la experiencia concreta, limitada y contingente, de ignorancia, de prejuicios, y de la manipulación de la conciencia social por los resortes del poder de los intereses sociales d:: minantes.

-Los modelos de explicación e interpretación de las circunstancias sociales, de los factores que intervienen en la determinación de éstas, en una sociedad como la nuestra, donde las ciencias sociales apenas comienzan a implantarse y a organizarse para la investigación de la sociedad, contienen siempre elementos que sirven para fortalecer el dominio de ciertos sectores de intereses sociales dominantes, y los otros elementos que forman parte de esferas de valores en conflicto con los dominantes, se derivan en gran parte solamente del fondo histórico de la tradición, y en ambos casos cuentan con todo el prestigio de su milenaria existencia.

Los resultados de la investigación científica, en el caso de ser conflictivos con los anteriores elementos, tienen, pues, que competir con tendencias psicológico-sociales de mayor prestigio y de mayorlpoder; porlo tanto, tuna de las constantes tareas, ha de ser siempre cuestionar las cosas que parecen evidentes y obvias para una determinada conformación de las estructuras perceptivas de la población, fortalecer los elementos de conciencia social que son confirmados por la investigación, y luchar enérgicamente contra el dominio de sistemas de explicación e interpretación del mundo social que contradicen los resultados de la investigación científica.

Por estas mismas causas, los resultados del desarrollo de una ciencia social no pueden menos que afectar, de un o de otra manera, los intereses de los diversos grupos que participan en una sociedad, cuya íntima entraña se trata de sacar a luz en la investigación. - Es, para usar una imagen tosca pero útil, como si Ud. se dedicara a observar sistemáticamente y a mostrar públicamente la más recóndita y profunda intimidad de la vida de una familia cualquiera: Porque debe ser, sin duda, excepcional una familia de cualquier sociedad, que pueda ser apta para ser exhibida en público, en su más obscura intimidad, sin rubores y sin enconos. 
- El estudio y la revelación de la naturaleza más profunda de la cstructura de una sociedad, se parece demasiado a eso. Es el desocultamiento de una realidad que muchos quisieran oculta siempre; respecto de la cual existen imágenes cuidadosamente distorsionadas y sútilmente engañosas, para que nadie pueda tener una conciencia correcta y clara de la situación y pueda, si necesario, considerarse con derechos a reclamo y con las pruebas en la mano. -

Porque no ocurre lo mismo en el tratamiento científico de la naturaleza que en el estudio de la sociedad. Este afecta, inevitablemente, intereses sociales, porque los pone en evidencia y muestra los factores y los resortes de su existencia. Intereses sociales que están, con frecuencia, empeñados en impedir el conocimiento público de su genuina naturaleza: dueños, casi siempre, de poderosos mecanismos de control de la imaginación y de la conducta colectivas, hábiles para fabricar imágenes e ideas que orienten la conducta colectiva en beneficio de aquellos intereses. Todo ello ha sido y sigue siendo un obstáculo permanente para el desarrollo de uñ ciencia social, plenamente poseída de la conciencia de si'e finalidades y alcances fundamentales, $y$, sobre todo, para una correcta utilización de sus resultados.

- Aun en sociedades más democráticas -y la nuestra es profundamente antidemocrática- las ciencias sociales, y de manera especial la Sociología, forman algo así como ciencias de oposición, con todas las dificultades y los riesgos implicados en esta situación, sobre todoen un período en que los grupos dominantes comienzan a perder el prestigio tradicional frente al resto de la sociedad, están menos seguras de su legitimidad y de su poder frente al desafío de las fuerzas de cambio, y tienen que recurrir a todos los recursos disponibles para defender su posición en la sociedad..

La maduración y la acẹleración del proceso de racionalización de la vida humana, que se reconoce como uno de los rasgos más poderosos de nuestro tiempo, podrán limpiar de estas vallas el camino de desarrollo de una genuina ciencia de la sociedad, y en la medida en que la propia ciencia st:a capaz de contribuir, inclusive en las condiciones más desfavorables, a la maduración de ese proceso.

Por supuesto, nadie tiene que olvidarse de que los propios sociólogos son parte de alguno de los grupos de interés en la sociedad en que investigan. De ello se derivan consecuencias que, en este nivel de nuestro análisis, deben aparecer claras, y sobre las cuales no es por eso necesario insistir 
demasiado. Pero en una sociedad como la peruana, estos problemas tienen algunas manifestaciones e implicaciones particulares que es indispensable señalar, aun cuando aquí no es posible hacerlo sino de manera sumaria.

-A diferencia de anteriores periodos de la historia de nuestra sociedad, en que los intelectuales provenian, básicamente, de las clases tradicionalmente dominantes, en los últimos cuarenta años el proceso global de modificaciones segmentarias y moleculares de la sociedad, ha conducido a la lenta y progresiva emergencia de heterogéneos estratos intermedios, principalmente en las zonas urbanas, a cuyas manos se ha ido desplazando claramente el cultivo de la actividad intelectual. .

De una parte, la clase dominante de la sociedad se ha modificado sustantivamente; ha dejado de ser predominantemente oligarquía terrateniente, para convertirse en una burguesía dependiente, que se recluta entre los grupos de terratenientes vinculados a la producción de agricultura industrializable y de exportación, de los grupos dedicados al comercio internacional ẹn gran escala y de los grupos financieros: Como es comprensible, esta división tiene solamente valor analítico, puesto que en la realidad estos estratos y grupos se superponen y se confunden hasta formar una clase integrada cuyos intereses sociales generales son coincidentes, aunque sus intereses de grupo o de estrato puedan ser en algunos aspectos contradictorios. - En gran parte, son las mismas familias, los mismos grupos y los mismos individuos que participan en cada uno de los sectores integrados en la nueva nueva clase dominante, que ces una burguesià dependiente.

La tendencia empresarial que no puede dejar de caracterizar a esta nueva clase dominante, la penetración de una estructura de mercado en todos los sectores de la sociedad peruana, han modificado decisivamente la clase de motivaciones y de tendencias ocupacionales de los miembros de la nueva clase dominante, a nivel nacional, y contribuido al surgimiento de una clara falta de interćs, hostilidad declarada con frecuencia, por las actividades de tipo intelectual.

Por estos factores, principalmente, la intelectualidad peruana contemporánea se recluta casi exclusivamente de los estratos que van constituyendo una clase media urbana nacional, que en los últimos años irrumpe aluviónicamente en la sociedad peruana, se convierte en uno de los estratos sociales mayores de ella, comienza a ganar influencia y participación en todas las esferas de la vida nacional, incluyendo el poder político. 
Pcro, por los mismos factores, la actividad intelectual, está penetrada y conducida por nuevos elementos y se mueve dentro de nuevas tendencias. - La intelectualidad tradicional, proviniendo principalmente de las clases dominantes, era una intelectualidad alienada, desarraigada de su propia realidad social nacional, vuelta de espaldas a ella o impregnada de cierta perspectiva filantrópica amorfa y vaga acerca de los otros sectores de la población. Su proceso de desalienación es un proceso tardío, que coincide con la entrada de las primeras capas de clase media en la escena nacional. Pero, al mismo tiempo, era una intelectualidad económicamente independiente, que se mantenía de su propio poder económico, y que se revestía del prestigio social de su clase.

Por el contrario, la intelectualidad contemporánea es cada vez más dependiente económicamente, y carente del prestigio social de que su propio estrato no dispone. La actividad intelectual libre, en estas condiciones, tiene un margen de existencia más y más estrecho. La propia naturaleza de la actividad intelectual tiende, en consecuencia, a modificarse sustantivamente. Ya no tiene la posibilidad total de incluir en su órbita la amplitud de intereses, la riqueza de problemas y prcguntas, que caracterizaban a la actividad intelectual tradicional peruana.

De ello se deriva, en su parte más importante, la tendencia hacia la profesionalización y la burocratización del intelectual peruano contemporáneo. IA mismo tiempo en que madura su proceso de desalienación, en el sentido de que está obligado a recoger en sus preocupaciones y en su actividad diaria los problemas más concretos de su propia sociedad, está obligado a participar activamente en ella y a impregnarse de sus notas más destacadas y efectivas, otro proceso de alienación oscurece su horizonte, obligado como está a depender de su trabajo para ganar su sustento, sometido a la reducción progresiva de sus horizontes mentales, de su campo de intereses y de preguntas, a la reducción de la problemática global en la que está concernido.

La desalienación es, por una parte, la consecuencia de la propia extracción social del intelectual, que proviene cada vez más de las capas bajas de la clase media, impregnada de los valores peculiares que se derivan del proceso de integración y de conflicto cultural en el cual se desarrolla lá nueva clase media. Pero la nueva alienación, proviene en la misma medida, de la situación que su grupo social de pertenencia detenta en la sociedad global.. 
La profesionalización, por una parte, implica la sujeción creciente a una actividad concreta determinada, en la cual está obligado a sumergirse en una profundidad creciente, pero en una amplitud decreciente, como parte de las tendencias de especialización profesional máxima insertas en la actualidad, como condición de alcanzar autoridad profesional y status económico-social decoroso.

La burocratización, esto es, su obligado ingreso en organizaciones burocratizadas, de tipo académico, en la empresa privada $o$ en las organizaciones estatales y para-estatales, lo sujeta, por otra parte, a un conjunto de normas de actividad, que en una sociedad en gran parte tradicional que se moderniza, contienen abultadas dosis de arbitrariedad y noracionalidad. La personalidad misma, en tales condiciones tiende a hacerse burocrática, esto es, formalista y ritual, atenida a las normas más bien que a las finalidades efectivas para las cuales se establecen las normas, y a los postulados mayores de la acción. El intelectual en este marco ve llenarse su tiempo de actividad sin trabajo, es decir de actividad que no es parte de un trabajo creador.

Sólo el talento y la vitalidad más vigorosos, o la más enérgica y desolada lucidez acerca de todas estas circunstancias, puede contribuir en alguna medida al rescate individual de Íos fueros de la inteligencia. Pero aún en estos casos, los confflictos de valor, los conflictos de lealtades, los conflictos de roles, sin duda harán terriblemente difícil la labor individual de organización de la personalidad, y un grado considerable de marginalidad social $\mathrm{y}$ usicológica parece inevitable .

En términos generales, el sociólogo, como cualquier hombre de ciencias sociales, forma parte de los grupos intelectuales de la sociedad. La ardiente naturaleza de los problemas sobre los cuales elabora sus preguntas, incluye por su riqueza $y$ por su profundidad, algunos de los núcleos básicos de la problemática intelectual de todos los tiempos.

En una sociedad subdesarrollada, cuyos problemas se agudizan por la naturaleza del sistema de dominación social vigente o por İos que se derivan del conclictivo y secular proceso de integración cultural, toda la problemática anteriormente bosquejada cobra dimensiones dramáticas. Y, obviamente, el hombre de ciencias sociales que, por su propia actividad profesional, está obligado a cuestionar y estudiar estos fenómenos, sufre todo su impacto.

Pero es, también, en su propia actividad, en la natura- 
leza de los problemas con los cuales está obligado a trabajar, donde residen sus más claras posibilidades de remontar, hasta donde sea posible en cada momento histórico, el horizonte de la nueva alienación que se le ofrece. En tanto que hombre de ciencia, y en tanto que intelectual, está mejor armado que muchas otras de las profesiones intelectuales, para comprender la naturaleza efectiva de los problemas y de los factores que podrían contribuir a su alienación, para explicitar los elementos subjetivos que provienen de las experiencias acumuladas en su formación individual, en el marco social y cultural del cual proviene, para contrastarlos con los datos de su investigación, para reorientar su percepción de los problemas, para tratar de sobrepasar los condicionamientos sociales que podrian influir en su tarea de construcción de la ciencia y en la tarea de construir un modo de ser.

El individuo no forma parte de su clase sino en tanto que individuo medio de la clase, y no está por lo tanto sujeto de manera definitiva e irrevocable a esta clase de condicionamientos. De la misma manera, una orientación cultural pluralista, la apertura universal del pensamiento, pueden siempre permitirle remontar algunos de los más duros condicionamientos de su marco histórico-social global, en el nivel de la conciencia.

Pero, la condición en el punto de partida es la adquisición y la elaboración de una muy clara y coherente conciencia de toda esta problemática.

\section{LAS TAREAS DELSOCIOLOGO ENLAISOCIEDAD PERUANA.}

Sobre el tclón de fondo del bosquejo analítico precedente, es posible ahora trazar algunas de las líneas principales que pueden servir para orientar la formación y la actividad del sociólogo en el Perú, y los rasgos básicos de la imagen del hombre que aquí se postula.

Dentro de los límites de este artículo, sólo podemos pretender cumplir este objetivo de manera enumerativa y sumaria, sin ánimo de agotar el análisis del problema y considerando que se deja claramente establecido que el propósito general del trabajo, es plantear algunos puntos de partida para el necesario debate en torno de estos y otros problemas que levante la implantación de la investigación científica de nuestra sociedad.

1.-En primer término, para hacer frente a toda esta compleja problemática, los sociólogos requieren de un tipo de 
formación que rebase largamente las restricciones exclusivamente profesionales. La formación básica no puede dejar de ser tan ancha y tan integrada como sea posible para cada individuo, si lo que se persigue no es la formación de un grupo más de profesionales técnicos, simplemente.

Lo que esa exigencia pone de relieve inmediatamente, en el contexto andino quizás más que en otras áreas de Latinoamérica, coincide en muy amplia medida con el reciente desarrollo de la colaboración interdisciplinaria en las ciencias sociales, que es parte de la tendencia a la reintegración del saber sobre la sociedad.

Por un lado, asistimos al eclipse de la tradicional imagen atomística de la sociedad, que caracterizó el apogeo de la sociedad burguesa. De ella se derivó, en buena parte, la tendencia anterior de desarrollar las ciencias sociales, como compartimientos estancos, separados por barreras infranqueables, y que se robusteció bajo la presión del marco institucional académico y del mercado profesional. Al desarrollo de la Sociología se debe, tanto como al proceso de cambio de la sociedad misma, la cancelación de esta imagen tradicional de la sociedad, y este es el sentido de la formulación sorokiniana de una "sociologización" de las ciencias sociales.

El aislamiento analítico y metodológico de diversos aspectos de la vida del hombre en sociedad, ya no puede continuar como hasta aquí aislado en la realidad. El campo de estudio de las ciencias sociales es el mismo para todas, aunque cada una puedá reclarhar ciertos objetos "específicos dentro de éi y elaborar enfoques y métodos adecuados para su estudio. En la medida en que es común el campo de estudios, las tronteras entre las diversas ciencias de la sociedad no pueden dejar de ser siempre provisionales y precarias; lejos de constituir límites definidos por la propia realidad, son límites definidos por las necesidades de su estudio, según las posibilidades de desarrollo de la ciencia en cada período histórico.

Con la tradición anterior todavía vigente, el desarrollo de la colaboración interdisciplinaria entre las ciencias sociales, no puede llevarse a cabo en la práctica, con todas sus implicaciones. Contra ella conspira la propia formación segmentarizada de los profesionales, en primer término, y las deformaciones introducidas en cada una de las ciencias por la tradición anterior, como es el caso característico de cierta Economía que todavía se enseña y se practica en muchas par- 
tes, y que comienza a introducirse en algunas universidades peruanas recientes.

Es indispensable, en consecuencia, no solamente la modificación de las ciencias mismas, para estar en condiciones de integrarse en la investigación, de construir una imagen integrada de la sociedad, que pueda resultar del nivel de los estudios en cada momento, sino también la radical reorientación de los sistemas de formación de los profesionales de las ciencias sociales.

Eso quiere decir, ante todo, que no es válido ni fecundo pretender la formación de sociólogos solamente sociólogos, de antropólogos solamente antropólogos, de economistas solamente economistas, etc., etc.

Todo lo contrario, la exigencia consiste en tratar de formar-hombres de ciencias sociales, con una formación básica lo más integrada posible, capaces no solamente de conocer y de manejar los resultados de las investigaciones de las otras disciplinas, sino también de manejar sus enfoques y sus instrumentos metodológicos, si es necesario.'

Nada de eso supone que un hombre de ciencias sociales no esté centrado en alguna de las disciplinas existentes hasta ahora o que puedan. desarrollarse en el futuro, en tanto que profesional. Pero no se puede pretender, en cambio, la continuidad del estilo de la formación tradicional, que no solamente fija al individuo en una disciplina, sino que le impide el conocimiento directo y el uso de los instrumentos conceptuales y metodológicos de las otras disciplinas.

En el área andina, la naturaleza compleja de los fenómenos socio-culturales, no puede ser cabalmente rescatada en la investigación científica, sin una perspectiva integrada en qu: participen conceptos y métodos de las diversas disciplinas. $\mathrm{Y}$ en un momento en que no existe todavía un número suficientemente grande de profesionales en cada una de ellas, ni un nivel relativamente seguro y generalizado de conocimientos e ideas acerca de estos fenómenos, la labor de investigación no puede ser llevada a cabo adecuadamente, sino por gentes con una formación básica en que se integren los más importantes elementos de las ciencias sociales básicas.

En la reciente reunión de ciencias sociales organizada en Santiago, por el Centro de Investigaciones de Historia Americana, de la Universidad de Chile, el Profesor John Murra dio 
un paso más en esta dirección: propuso la posibilidad del abandono del esquema divisorio de las ciencias sociales existentes, para comenzar a trabaịar no tanto dentro de cacla disciplina, sino en torno a núcleos de fenómenos y problemas. La sugestión es extraordinariamente interesante, y es necesario continuar explorando esta posibilidad.

2.-A partir de lo anterior, la investigación científica de nuestra realidad, no sólo en las ciencias sociales, impone la cancelación del estilo tradicional de trabajo en este campo. Como es sabido, la investigación anterior se caracteriza por un énfasis desmedido en el trabajo individualista, por la propensión al ensayismo, por la discontinuidad entre las investigaciones y por un prurito de virginidad de los objetos de estudios.

La magnitud de la tarea que se levanta ante nosotros, en una sociedad donde hay tan poco hecho en la dirección que requerimos obliga a que el estilo tradicional de investigación científica isea cancelado lo más prontamente posible.

- En el Perú, como en todos los demás países del área andina, estamos atravesando un periodo de transición entre el ensayo y la investigación empírica o concreta. Nadie puede en este momento recusar el valor de la obra de los ensayistas de nuestra historia anterior, puesto que esa obra constituye la delgada capa de conciencia social y de comprensión inteligente que forma nuestra actual atmósfera de ideas y de conocimientos acerca de nuestras sociedades.S Pero la continuidad de este estilo de trabajo requiere para ser fecundo en este período, ser realizado ya no en tanto que un modo no sistemático, impresionístico y difuso de reflexión sobre la realidad, sino en tanto que un conjunto de hipótesis provisorias construidas con la finalidad específica de su verificación empírica. Es decir, pasar a formar parte del trabajo mismo de la investigación cientifica.

Por otra parte, el individualismo en el trabajo científico, con sus resultados conocidos de inorganicidad de las investigaciones, de falta de continuidad y de programación, con su énfasis desmedido en la pura originalidad de las investigaciones y en la virginidad de los objetos de la investigación, son ahora más nocivos que antes. "La necesidad de contribuir a desarrollar la ciencia, además de comenzar a contribuir a elaborar algunas respuestas para los más urgentes interrogantes y problemas de la sociedad, exige la programación, la sistematización, la continuidad de las investigaciones. Ello 
supone trabajo de equipo, coordinación e interdependencia de las investigaciones que se realizan por las varias disciplinas y centros de investigación sobre los mismos problemas, y el abandono del prurito de la virginidad del campo de estudios, para ser reemplazado por la exigencia de continuidad de las investigaciones anteriores. En verdad, en este terreno todo está casi virgen y casi todo está virgen, si ello sirve de consuelo a los que todavía no tienen la disposición a desprenderse de las muletas tradicionales.

En consecuencia, parte del esfuerzo de formación básica de los futuros hombres de ciencias sociales, así como de la organización de los centros de investigación y de trabajo para ellos, no puede prescindir de tener en cuenta estas consideraciones y tratar de llevarlas a la práctica en la medida de las posibiliclades de cada momento.

3.-Para que lo anterior pueda ser desarrollado en la práctica, para que sea posible organizar las investigaciones de manera programada y sistemática, hay una tarea indispensable que llevar a cabo.

Puesto que no disponemos de ningún enfoque teórico acerca de la sociedad peruana, en general, o acerca de núcleos determinados de fenómenos y problemas de nuestra sociedad, organizados como para ser llevados a la prueba inmediata de la investigación empírica o concreta, no se puede pensar en la posibilidad inmediata de programar investigaciones concretas, de manera coordinada y sistemática. Entre tanto, las investigacionesude tipo descriptivo y segmentario, no pueden dejar de continuar. •

Pero si se admite la necesidad de comenzar a trabajar de manera programada, sistemática e interdependiente, la tarea básica necesaria es la elaboración de enfoques provisionales, organizados como sistemas de hipótesis destinadas a la investigación concreta, acerca de conjuntos de fenómenos sociales básicos de la sociedad:'

Podría argüirse que esta tarea no puede ser llevada a cabr. precisamente porque no contamos con resultados de investigaciones previas. Pero esta es sólo una verdad a medias. En realidad, en la investigación científica de nuestra sociedad no estamos partiendo de cero. Existen ya, de una parte, todo el fondo de concepciones presociológicas que se están utilizando en este mismo momento para fundar la práctica política, económica, social, especialmente en torno del problema del desarrollo económico. Tales concepciones necesitan ser pasadas 
por el fuego de la investigación, y para ello es necesario organizar hipótesis de trabajo con los elementos más importantes de estas concepciones presociológicas acerca de nuestra sociedad. De otra parte, toda la tradición del ensayo y de la filosofía social anterior de nuestros países, así como los resultados de investigaciones ya realizadas, en la Antropología, en la Economía, en la Historia, aunque escasas y de nivel más bien descriptivo, proporcionan una riquísima fuente de hipótesis y de teorías que deben ser sistemáticamente exploradas y organizadas para ser llevadas a la investigación concreta.

Estos enfoques teóricos provisionales, deberán servir para guiar la investigación, para plantear las preguntas básicas a la realidad, que la investigción empirica deberá contestar, para orientar la programación y la interdependencia de las investigaciones.

- Junto a todo ello, todo el aparato teórico desarrollado sobre la base de la investigación en otras sociedades diferentes y muy industrializadas, y en aquellas que forman el mundo subdesarrollado fuera de Latinoamérica, constituyen sin duda el más importante reservorio de teorias e hipótesis de trabajo, que deben ser investigadas concretamente en nuestra sociedad.

Aquí se plantea, sin embargo, un problema de la más grande importancia para el destino de las ciencias sociales en nuestras sociedades. Ya hemos destacado anteriormente, el hecho de que gran parte de este aparato conceptual y metodológico desarrollado en la investigación de otras sociedades, muy especialmente en las sociedades industrializadas, aparece viciado por un claro etnocentrismo científico, por una visión provinciana de los fenómenos, por muy alto que pueda ser su grado de elaboración y de sofisticación, y que, sobre todo, una tendencia muy generalizada de la teoría sociológica contemporánea tiene un sello de ahistoricidad, correspondiendo en una apreciable medida a la naturaleza de los intereses sociales dominantes en aquellas sociedades, que son, rara coincidencia, los mismos intereses dominantes en nuestras propias sociedades.

1De eso se desprende, en consecuencia, la necesidad aguda de un replanteamiento del aparato conceptual y metodológico elaborado para sociedades distintas, con el propósito de utilizar lo que es realmente adecuado para dar cuenta de nuestra propia realidad, de retener y desarrollar lo que puede tener validez universal efectiva testado en esta realidad y en otras, de reformular, ampliar y enriquecer la elaboración científica alcanzada hasta aquí, y de rechazar resueltamente lo que un 
examen teorético minucioso y cauto y la investigación efectiva revelen como inadmisible.

Aprender a despojarse de la tradicional actitud de reverencia por todo lo que viene de las sociedades de las que dependemos, aprender a construir un fondo propio de conocimientos y de icleas acerca de nuestros propios problemas y fenómenos básicos; ser consecuentes con la honesta actitud de rechazo del criterio feudal de autoridad como prueba de la bondad de las afirmaciones y postulados, será sin duda muy difícil en un período en que las tendencias opuestas rigen tanto de la vida de nuestra sociedad. Pero no puede dejar de ser hecho, desarrollado y generalizado enérgicamente.

- Todo ello significa, en el fondo, una tarea mucho más compleja y difícil. Tratar de construir ciencia a partir de nuestra propia realidad, como el camino más fecundo y largo de contribución al desarrollo de nuestras disciplinas. Elaborar conceptos nuevos para fenómenos nuevos, cuya naturaleza no puede ser, con frecuencia, captada a través de estructuras perceptivas armadas para otra clase de circunstancias, es acaso la más difícil pero la más importante tarea de los hombres de ciencias sociales en nuestra sociedad, en tanto que hombres de ciencia.

En la actulidad ya existe una conciencia bastante desarrollada acerca de esta problemática entre los hombres de ciencia social de otros países de Latinoamérica, a medida que sus propias investígaciones han ido poniendo de manifiesto que la mera aplicación mecánicácelifrestricta de los esquemas teóricos elaborados desde fuera de estas sociedades, no solamente es insuficiente para dar cuenta de lo que ocurre aquí, sino, lo que es sin duda más decisivo, que conduce en gran parte a una distorsión de la realidad en la abstracción.

Esto se refleja en este momento, de manera más clara y más aguda, en las investigaciones sobre los fenómenos de cambio socio-cultural que atraviesan nuestras sociedades. La ahistoricidad inserta en la óptica sociológica de algunos enfoques muy prestigiosos en el mercado académico corriente, la pretensión de "objetividad" y de "neutralidad" que, no obstante, reclaman, son, sin duda, algunos de los más serios escollos para la compresión de la naturaleza genuina de los fenómenos específicos de cambio, que toman parte en la historia actual de nuestras sociedades y en las del área andina más que en ninguna otra, por obvias razones.

Los hombres de ciencia social que quieran realmente apre- 
sar en la elaboración científica los fenómenos de su propia sociedad, y que pretendan contribuir al desarrollo de su propia disciplina, no pueden eludir las responsabilidades y tareas implicadas en esta situación.

4.-La sociología aparece en el Perú en un momento de dramática urgencia de resolver los problemas acumulados a lo largo de siglos, urgencia que se desarrolla a partir de la generalización de la conciencia de los problemas en la sociedad, y de la entrada en escena de radicales fuerzas de cambio de la estructura tradicional y modernizante de la sociedad. Por aparecer en esta hora histórica, la ciencia sociólogica recibe inmediatamente una presión cada vez más dura, para proporcionar respuestas adecuadas a las interrogantes que los problemas de la sociedad plantean, particularmiente en relación a los problemas de cambio que se perciben como "desarrollo económico".

No queda, pues, prácticamente ningún margen para la investigación "pura", no vinculada a problemas concretos del día. Y, no obstante, la ciencia sociológica no puede proporcionar ninguna clase de respuestas realmente importantes y válidas para estas demandas, sin llevar a cabo investigaciones básicas, es decir, sin investigar fenómenos sociales básicos, no solamente su manifestación en forma de problemas urgentes, aún cuando estas investigaciones pudieran parecer a muchas gentes como desprovistas por completo de finalidades concretas inmediatas.

El dilema resultante para la investigación sociológica, pucđe tener, a pesar de todo, algún camino de resolución. Puesto que, por una parte, los hombres de ciencia social no pueden, ni deben, eludir el compromiso que su sociedad impone, están obiligados a llevar a cabo investigaciones destinadas a proporcionar alguna respuesta, por provisoria que sea, a los problemas más acuciantes de este momento. Puesto que, para cumplir realmente esta tarea, en el nivel de la ciencia, el desarrollo de la ciencia misma es indispensable, esto es, indispensable investigar los fenómenos básicos que subyacen en los problemas concretos, en tanto que hombres de ciencia los sociólogos no pueden, ni deben, eludir el reclamo de su propia disciplina.

En tales circunstancias, la salida más viable y fecunda puede ser una solución metodológica. Se hace necesario organizar diseños de investigación que puedan ser útiles para ambas finalidades. Esto es, diseños de compromiso. Se sabe de antemano que este no es el camino ịdeal para el desa- 
rollo de la ciencia misma. Pero se sabe también de antemano, que otra posibilidad tiene un margen muy estrecho y precario.

Estos diseños de compromiso, consisten en un modo de organizar los proyectos de investigación, incluyendo, al mismo tiempo, las preguntas derivadas de los problemas prácticos que hay que solucionar, y para investigar lo cual, seguramente, se obtendrán los recursos institucionales y financieros necesarios, y las preguntas que permitan obtener información acerca de los fenómenos básicos en los cuales el investigador está interesado en tanto que hombre de ciencia. Implican, entonces procedimientos y técnicas de recopilación y de análisis de la información, que permitan hacer las dos cosas al mismo tiempo, o, por lo menos, tener material para una elaboración científica como tal, en una segunda instancia.

El problema aquí, es que siempre que se habla de investigación, una muy definida influencia que se origina en las sociedades de gran desarrollo económico, que cuentan con grandes centros de investigación y con instituciones de financiación de aquellos, con gran número de investigadores entrenados en el más alto nivel, disponiendo de recursos de todo orden, hace que también en nuestras sociedades, que se caracterizan por carecer de todos estos elementos, se tienda inmiediatamente a pensar en términos ajenos. Es decir, en un complicado aparato burocrático y financiero, sin cl cual no sería posible tlevar a caboeinvestigaciones, y en un atuendo técnico ultra-sofisticado, para el cual, naturalmente, no se puede prescindir de todo aquello.

Si la investigación científica se hubiera llevado a cabo siempre en las condiciones propias de las actuales sociedades industrializadas, ni éstas serían industrializadas, ni tendríamos ninguna clase de investigaciones científicas. Nuestras sociedades no disponen, precisamente porque son subdesarrolladas, de los recursos de investigación de las sociedades industrializadas. Tomar como argumento la carencia de estos recursos, para justificar la carencia de investigaciones, supone mucho más tomar un pretexto para no hacer las investígaciones.

' De la misma manera, se trata de calcar modelos institucionales de sociedades de otra naturaleza y de otras posibilidades; de la misma manera se exige en todos los sectores sociales opuestos a cierto tipo de cambios como la reforma agraria, la necesidad de contar con estudios técnicos perfec- 
tos y completos sobre todos los problemas que puede suscitar el fenómeno, antes de proceder a realizar la reforma; de la misma manera, se organizan costosas e inútiles maquinarias burocráticas, que so pretexto de organizar y planear el desarrollo, parasitan los desfinanciados presupuestos nacionales. De la misma manera demasiadas cosas para ser repeti$\mathrm{ds}$, que denuncian una actitud terriblemente torpe y carencia de una comprensión creadora de las circunstancias en que se cumple la labor de la cultura. Eso es parte de la sociología de la dependencia.

Nuestra sociedad está demasiado urgida de investigaciones, como de cambios sustantivos. No podemos darnos el lujo de encontrar previamente las óptimas facilidades y recursos para llevarlos a cabo. Sin duda alguna los sociólogos están equipados para comprender cabalmente lo que todo eso significa, y no dejarán de hacer lo que deben, cualesquiera que sean las condiciones y las posibilidades, con máquinas o sin ellas, con grandes aparatos burocráticos o sin ellos, con el más refinado instrumental metodológico, o con alguna artesanía metodológica donde la imaginación y la iniciativa individual inteligente, permita, a pesar de todo, cumplir la tarea para la cual se fue formado.

5.-Puesto que hemos de vivir y trabajar como hombres de ciencias sociales, en una sociedad cuyas estructuras sociales y psicológico-sociales contienen costras tradicionales, como resultado de lo cual los problemás se encaran con prejuicios, concepciones pre-científicas, con la desnuda ignorancia unifor. mada de poder, conlas semi-verdades cque la experiencia inmediata entrega; puesto que ninguna ciencia, y mucho menos una ciencia social, puede desenvolverse plenamente sin contar con una atmósfera de conocimientos e ideas adecuada, en el plano colectivo; puesto que el desarrollo de estas disciplinas tropezará con la manipulación de las conciencias por los recursos del poder, y la misión de una ciencia de la sociedad es también la clarificación y el enriquecimiento de la conciencia social de su sociedad; puesto que todo eso es asf', los hombres de ciencias sociales en general y los sociólogos en particular, no pueden dejar de cumplir una otra tarea ineludible: la reorientación de la opinión pública en función de los resultados de las investigaciones, lo que conlleva la obligación de combatir, enérgica y pacientemente, las preconcepciones sociales incompatibles con el desarrollo científico del conocimiento de la sociedad!

El sociólogo peruano no ignora sin duda las dificultades 
y ricsgos que esta tarea implica. A nivel individual, hay que optar. Pero la opción debe ser lúcida, para ser perdurable.

\section{UN RASGO ESENCIAL DE LA PROFESION DE SOCIOLOGO}

Por la naturaleza de los problemas y las tareas que el sociólogo debe enfrentar en la sociedad, que acaban de enumerarse sumaria y no agotadoramente, es claro que la imagen del profesional que aquí se postula, difiere radicalmente de la que se atribuye a otras profesiones. El profesional que aqui se postula no es un técnico.

$\mathrm{Si}$ se considera que, estrictamente, el técnico está fundamentalmente preocupado por problemas de eficiencia, abandonando a un lugar secundario o, con frecuencia entre nosotros, absolutamente los problemas de postulado, ello implica que el técnico no se pregunta por la naturaleza de las finalidades mayores que se persigue con la aplicación de un conjunto de conocimientos, ni por las repercusiones a largo plazo de su acción.

El Sociólogo y todos los demás hombres de ciencias sociales, incluídos los economistas, por el contrario no pueden dejar de hacer, de ninguna manera, lo que los técnicos no hacen, sin poner en juego la condición misma de su personalidad y de su actividad.

Como afirmal JoséMedina Echevarría, S una de las más lúcidas autoridades de la sociológíacn/lengua española, el Sociólogo pertenece: "dentro de la extensa familia de la inteligencia, a los capaces de mantener una actitud crítica y no meramente técnica". (3)

Si se trata de obtener el conocimiento científico de los problemas del hombre dentro de la sociedad, ello implica el esclarecimiento constante, de lo que tales problemas significan para la vida concreta de hombres concretos. La clarificación permanente de la conciencia social de los grupos humanos, debe otorgar a los hombres la posibilidad de replantarse en cada momento el sentido de su historia, la posibilidad de intervenir de manera racional y consciente en la creación y recreación inceșante de las condiciones concretas de su existencia social.'

Si la explicación científica de los factores que intervie-

(3) JOSE MEDINA ECHEVARRIA: Aspectos del Desarrollo Económico. Santiago de
Chilc, 1959. 
nen en la vida social, permite al hombre eliminar las alienaciones más fuertes de cada período histórico concreto, si ello significa la maduración de la libertad y la racionalidad que busca el hombre, las ciencias sociales no habrán sido ajenas a todo ello.

Los hombres de ciencia social en el Perú, deben saber, ahora, lo que buscan y lo que pueden lograr. Esta es la perspectiva y éstas las dificultades y los riesgos.

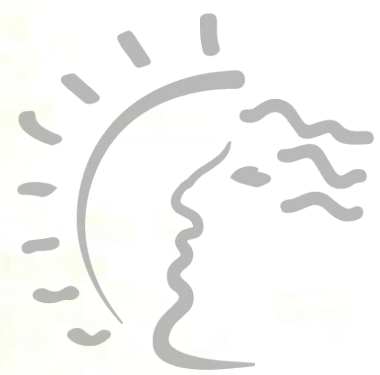

Biblioteca de Letras

"Jorge Puccinelli Convèrso" 